\title{
Repensar los exilios políticos latinoamericanos del siglo XX desde los márgenes: un comentario introductorio
}

\author{
Silvina Jensen* , Soledad Lastra**
}

En la última década, las historiografías del Cono Sur de América Latina vienen experimentando el notable crecimiento de los estudios sobre los exilios políticos. Si bien los exilios masivos de las llamadas "dictaduras de la Seguridad Nacional" han concentrado el mayor interés, en parte por el carácter masivo o más numeroso de esos movimientos poblacionales, pero en no menor medida por impulso de las heterogéneas políticas públicas nacionales de Memoria, Verdad y Justicia, el campo reconoce hoy una pluralidad tan grande de experiencias, subjetividades, lógicas y procesos de emigración política del pasado más próximo o más lejano, interrogados desde marcos disciplinarios y arsenales teórico-metodológicos tan diversos, que resulta difícil afirmar cuáles son sus señas de identidad.

Partiendo de tal estado de cosas, en este número de Revista de Historia y Geografía se incluyen cuatro aportes sustantivos que, en una temporalidad que recorre el siglo XX pero que hace foco en las dos coyunturas más significativas para la producción de exilios masivos, interpela el objeto "exilios políticos" desde los márgenes del campo de estudios.

Ahora bien, ¿por qué hablamos de márgenes? La respuesta no es sencilla.

\footnotetext{
* Argentina. Doctora en Historia. Profesora-Investigadora, Departamento de Humanidades, Universidad Nacional del Sur (Bahía Blanca). Consejo Nacional de Investigaciones Científicas y Técnicas (CONICET), Argentina. ORCID: https://orcid.org/00000002-9166-8852. E-mail: sjensen@criba.edu.ar

** Argentina. Doctora en Historia. Profesora-Investigadora, Escuela Interdisciplinaria de Altos Estudios Sociales (IDAES), Universidad Nacional de San Martín (UNSAM). Consejo Nacional de Investigaciones Científicas y Técnicas (CONICET), Argentina. ORCID: https://orcid.org/0000-0001-6619-8249. E-mail: lastra.soledad@gmail.com
} 
En primer lugar, consideramos que los trabajos aquí reunidos dan cuenta de sujetos, subjetividades y procesos que en buena medida no representan al canon de los estudios exiliares latinoamericanos.

En este sentido, si se analizan los exilios de intelectuales reconocidos - parcela del campo que en las últimas décadas ha experimentado una notable renovación, interesándose por la circulación de bienes simbólicos, el peso de las redes ideológicas y académicas, y la reconstrucción de interlocuciones culturales que rompen con la lógica jerárquica centro-periferia, cuestionando la vieja noción de "influencia"-, se elige la trayectoria de una mujer oriunda de Italia y filiada con el anarquismo, que no solo consiguió un lugar expectante en la conversación global sobre la experiencia fascista en el contexto de la Segunda Guerra Mundial, sino que lo hizo desde la periferia atlántica, en concreto desde Montevideo.

Del mismo modo, cuando se abordan las políticas de nacionalización en el Brasil de Getulio Vargas y sus efectos coactivos sobre los movimientos de sus habitantes, se opta por hacerlo desde una reconstrucción localizada y por fuera de las grandes ciudades y en una región de frontera. Cuestión que permite conocer los modos específicos de vivir los desplazamientos motivados por las violencias del Estado Novo y, al mismo tiempo, iluminar las tramas locales de la acción estatal en un territorio poroso, con comunidades de inmigrantes dispersas a ambos lados de la frontera internacional.

Asimismo, cuando incursionamos en los exilios de la Doctrina de la Seguridad Nacional lo hacemos con foco en una experiencia exiliar no solo poco conocida y minoritaria - la de los "banidos" brasileros (desterrados, "intercambiados")—, que tuvo como destino un continente marginal para el relato de los exilios de las dictaduras del Cono Sur (África); y lo hacemos también incidiendo en las complejidades de un instrumento de exclusión institucionalizado por el gobierno militar brasileño que, operando como un castigo para quienes habían desafiado la autoridad, ponía de relieve la eficacia de la resistencia de las organizaciones revolucionarias en un contexto dictatorial altamente represivo.

El último artículo dedicado a estas temáticas analiza un tema clásico de la historiografía de los exilios y también de las Relaciones In- 
ternacionales - los asilos diplomáticos y territoriales en el Cono Sur bajo las dictaduras de la Doctrina de la Seguridad Nacional-, pero lo hace historizando el trasiego de perseguidos y derrotados políticos y militares bolivianos hacia la Argentina, en un contexto de fuerte inestabilidad político-ideológica, institucional y social en la región, y preguntándose por sus efectos sobre las relaciones bilaterales, los equilibrios regionales y en la disputa global entre EE.UU. y la URSS en el tramo final de la Guerra Fría. Pero, al mismo tiempo, se propone poner en tensión una hipótesis fuerte en los estudios de los últimos exilios del Cono Sur, que tiende a pensarlos como epifenómenos de la "guerra antisubversiva" en el marco de la Guerra Fría. Cuestión que, en muchos casos, ha obturado la comprensión de la pluralidad de intereses y expectativas que alimentaban conflictivamente las políticas de los estados receptores de los asilados, del uso que los diferentes gobiernos y regímenes políticos hicieron de esta prerrogativa de la soberanía estatal y de la dificultad de convertir en sinónimos asilo y protección de los Derechos Humanos.

En segundo lugar, consideramos que los artículos aquí incluidos exploran otro margen del campo, porque en todos los trabajos se cuestiona la productividad de los modos clásicos de fragmentar espacialmente las experiencias exiliares. En este sentido, si bien no se excluye la territorialidad del Estado-nación, se apuesta por comprender multiescalarmente los procesos exiliares a lo largo del siglo XX, reponiendo tanto sus enraizamientos y sus tránsitos, como las salidas y los retornos. Y sin olvidar que los exilios políticos, en tanto objeto poliédrico, reclaman permanentemente pensar localmente lo regional y lo global y, a la vez, no divorciar las dinámicas territorializadas de sus impactos/ proyecciones y efectos internacionales.

En tercer lugar, este grupo de artículos recorre otro margen del campo, y hace un llamado a discutir la temporalidad de los estudios exiliares enfocados en el tiempo corto de las experiencias masivas de la segunda mitad del siglo XX y preocupados por remarcar la excepcionalidad de los exilios de la Doctrina de la Seguridad Nacional. En este punto creemos que, en su conjunto, estos trabajos ayudan a iluminar ciertas líneas de continuidad tanto respecto a los usos políticos como represivos de los exilios que, sin obliterar la novedad que supuso su democratización bajo imperio del terrorismo de Estado, revelan que 
estos no fueron ajenos a ciertas lógicas políticas, comportamientos estatales y culturas burocráticas de más largo aliento que hunden sus raíces en el siglo XIX y primeras décadas del siglo XX.

El trabajo de Ricardo Passolini titulado "Lecturas desde el exilio: Luce Fabbri y la interpretación del totalitarismo europeo", hace foco en la trayectoria personal, familiar y política de la intelectual anarquista Luce Fabbri en su exilio rioplatense entre 1936 y 1945. El autor se propone ingresar al "debate político transnacional del antifascismo italiano" en una coyuntura crítica y cambiante para los destinos de los fascismos europeos, atendiendo a las transformaciones operadas en la lectura del totalitarismo propuesta por Fabri mientras dirigía la revista Studi Sociali en Montevideo. Se trata de un ejercicio sugerente que reconoce, en el nivel micro y en la aproximación biográfica, herramientas idóneas no solo para interrogar procesos político-intelectuales complejos de alcance global de los que participaron diferentes grupos políticos, personas y publicaciones referenciadas con las diferentes "familias ideológicas del antifascismo europeo", sino también para iluminar el derrotero de una intelectual que inserta en una red de relaciones personales e institucionales exiliares, y desde la periferia atlántica supo construir un lugar de enunciación original, crítico y propositivo sobre la experiencia fascista.

El artículo de João Vitor Sausen titulado "La guerra y los no nacionales: la Segunda Guerra Mundial y las radicalizaciones de la Campaña de Nacionalización en Porto Novo, Brasil (1939-1945)", historiza las políticas de nacionalización de población extranjera impulsadas por el gobierno de Getulio Vargas en el contexto de la Segunda Guerra Mundial. El autor parte de la hipótesis de que la declaración de guerra del Estado Novo a las potencias del Eje supuso no solo la profundización de las estrategias asimilacionistas sobre la población germanoparlante de la región de Porto Novo, sino el diseño de otras abiertamente represivas, que incluyeron persecuciones, detenciones y desplazamientos forzados. Tanto las impulsadas por el gobierno local, que reubicó violentamente a colectivos considerados "peligrosos" en un movimiento de alejamiento de la frontera con la Argentina, como las huidas resultantes de la creciente violencia étnico-política que obligó a ciertos grupos a buscar la protección en terceros Estados, al amparo de redes familiares y de paisanaje cimentadas a un lado y al otro de las fronteras interestatales. 
Este grupo de artículos sigue con el valioso trabajo de Beatriz Figallo y María José Henríquez titulado "Geopolítica y asilo. Juego de intereses y principios en la relación argentino-boliviana, 1969-1972", que analiza los usos del asilo político en el marco de las relaciones internacionales en el Cono Sur de América Latina entre 1969 y 1972, con particular atención a los vínculos entre Argentina y Bolivia, en un contexto regional atravesado por la creciente radicalización políticasocial posrevolución cubana y la sucesión de gobiernos autoritarios y militares de perfiles diversos, que no solo libraban una "guerra" contra el "enemigo subversivo" en el marco de la Doctrina de la Seguridad Nacional, sino que hicieron del trasiego de opositores, militantes revolucionarios, golpistas derrotados, exiliados en sentido amplio y asilados diplomáticos y territoriales, una carta a jugar en la disputa geopolítica por el control de una región que tenía como uno de los interlocutores fundamentales a Brasil.

Con un sólido trabajo de archivo de fuentes diplomáticas y periodísticas, Figallo y Henríquez visibilizan la centralidad del factor geopolítico para comprender la historia reciente del exilio boliviano, mostrando que para comprender por qué Argentina operó como país receptor de asilados y exiliados bolivianos durante los gobiernos militares de Alfredo Ovando, Juan José Torres y Hugo Banzer no basta con identificar la matriz ideológica anticomunista, sino que es necesario reconstruir también cómo operaron los intereses económicos nacionales en las relaciones bilaterales y en la disputa por la hegemonía regional.

Finalmente, el trabajo de Débora Strieder Kreuz titulado “Del infierno al paraíso': el destierro de presos políticos brasileños para Argelia en 1970", analiza la experiencia de un grupo de 40 militantes de Vanguarda Popular Revolucionária (VPR) y Ação Libertadora Nacional (ALN), que salieron del Brasil rumbo a Argelia en junio de 1970 bajo una modalidad específica de exilio conocida como "banimento". El "banimento" fue una pena de expulsión institucionalizada por la dictadura brasileña que, ante la presión que implicaron los sucesivos secuestros a representantes diplomáticos extranjeros entre septiembre de 1969 y junio de 1971, decidió regular el modo en que aquellos brasileros considerados "peligrosos para la seguridad nacional" y que estaban encarcelados, podían recuperar la libertad a condición de salir del país. La propuesta de Kreuz ilumina la experiencia exiliar de los 
"banidos" en Argelia en sus dimensiones represivas y resistentes, pero también personales, familiares y socioculturales. A la vez, convierte el caso de los "trocados" por el embajador alemán - secuestrado mientras se celebraba el Campeonato Mundial de Futbol en México- en una ventana para pensar los usos estratégicos del exilio por parte de militantes revolucionarios y gobiernos militares, y en los modos en que el activismo transnacional de los exiliados formateó la agenda exterior de las dictaduras de la Doctrina de la Seguridad Nacional.

Cerramos esta presentación señalando que este cuerpo de artículos tiene un potencial añadido, en tanto pone en diálogo la producción de cinco investigadores de tres países (Chile, Brasil y Argentina), de distintas generaciones, con diferentes historiales académicos y que dan cuenta de variadas interlocuciones al interior de sus respectivos campos historiográficos nacionales. Pero todos interesados en analizar un fenómeno complejo que adoptó diversas formas (huidas, expulsiones, desplazamientos forzados, expatriaciones políticas) y estuvo regulado por diferentes instituciones (asilos territoriales y diplomáticos, "banimentos") a lo largo del violento siglo XX latinoamericano. 